\title{
HEALTH SCIENCES
}

\section{Where does the cranial base flexion take place in humans?}

\author{
RICARDO V. BOTELHO, PEDRO B. BOTELHO \& JULIETE M. DINIZ
}

\begin{abstract}
The modern human has the most flexed cranial base among all living animals. The flexure allowed a larger cranial volume to accommodate a greater brain. Sphenooccipitalis synchondrosis (SOS) has been largely responsible for cranial base flexion, between the sphenoid and the Pars basilaris of the occipital bone. The objective of this work is to evaluate the real place of skull base flexure. Analysis based on 50 magnetic resonance imaging from normal adult subjects were used to evaluate normal place for cranial base angulation (CBA). The vertex of the cranial base angle in all individuals occurred intrinsically in the sphenoid bone. In humans, cranial base flexure had a specific pre-chordal origin, rather than in the transition between pre-chordal and chordal plates and occurred in the inner sphenoidal bone.
\end{abstract}

Key words: anatomy, skull, base, embryology, body patterning, Platybasia, basilar impression.

\section{INTRODUCTION}

The skull base is formed by a cartilaginous template, created by several ossification centers joined by synchondrosis, known as chondrocranium. It is the most complex bone structure of the skeleton. (Lieberman et al. 2000).

There are two distinct embryological origins for the formation of the skull base: chondrocranium precursors, anterior to notochord, are formed from cells that condense on the prechordal plate, derived from the neural crest and the posterior mesodermal precursors, originating from the paraxial (parachordal or simply chordal) mesoderm (Cendekiawan et al. 2010, LeDouarin et al. 1993, Mcbratney-Owen et al. 2008, Seifert et al. 1993).

The prechordal plate develops pituitary cartilages (basisphenoid) and presphenoid cartilages. The chordal mesoderm originates from the occipital somites and gives rise to the parachordal cartilages, precursor of basioccipital (Pars basilaris).

The modern human skull (Homo sapiens sapiens) has the most angled skull base among all living animals. The cranial flexure allowed increase in volume to accommodate a greater brain, the frontal positioning of the eyes, vocalization and erect position (Nie 2005).

Great amount of research has been done in the last decades evaluating cranial base angle (CBA). Several works in CBA defines a plane between postchordal and the prechordal plate, especially in sphenooccipitalis synchondrosis (SOS) flexing in the midline, producing the cranial base angle (Couly et al. 1993, Lieberman et al. 2000, Micheda 1972, Nie 2005, Lieberman \& McCarthy 1999). SOS has been largely responsible for cranial base flexion, between the sphenoid bone and the Pars basilaris of the occipital bone [8]. Several authors suggest that CBA would be 
created in synchondroses, especially in SOS (Cendekiawan et al. 2010).

The objective of this study is to test the hypothesis that the flexure of the base of the skull occurs between the pre-chordal and chordal mesodermic plates (sphenooccipitalis synchondrosis) and to determine specifically the local of cranial base angulation in humans.

\section{MATERIALS AND METHODS}

This study was based on a database of Magnetic Resonance Imaging of the skull in normal subjects.

MR images of the skull were randomly selected from normal adult subjects, who underwent MRI for some symptom in which no tumor, infectious or any type of abnormalities were identified, without any craniocervical malformation, in which sos synchondrosis was already mature, consolidated, avoiding the possibility of the flexure of the base of the skull being still in formation. The base of the human skull flexes rapidly after birth, almost entirely before two years of age (Lieberman \& McCarthy 1999, Lieberman et al. 2000).

The following annotations and measurements were made in images, in midline T1 weighted acquisition:

1) Identification of the location of the CBA. Should be the angle made at the cranial base flexion (Figure 1).

2) Measurement of CBA. Due to the frequent prominence of Jugum sphenoidale and Sinus sphenoidalis to inside skull base, in midline, making it difficult to proper jugum sphenoidale identification, the anterior cavity plane was measured from the Sutura frontonasalis to the top of the Dorsum sellae (Figure 1).

The posterior sphenoid plane was measured between a point immediately below the Dorsum

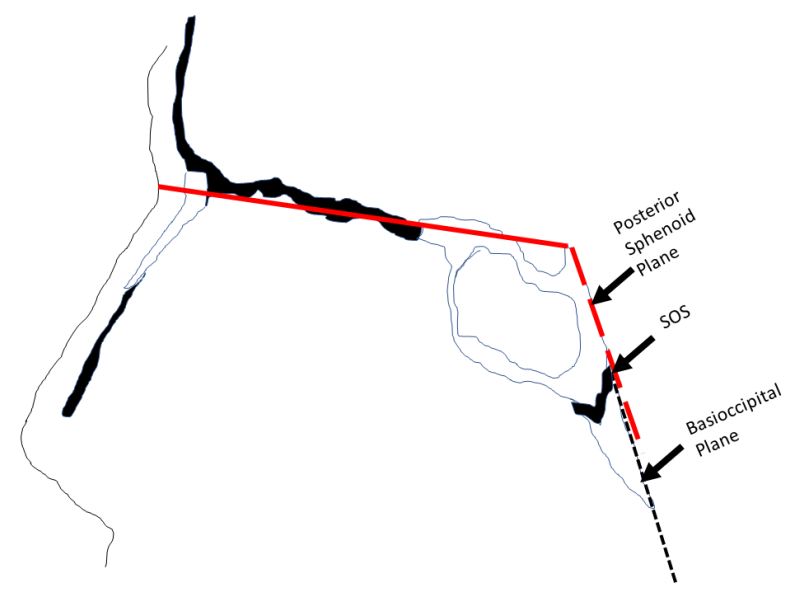

Figure 1. Schematic visualization of angular measurements. Cranial base angle (CBA) was identified in all subjects as occurring between Nasion, top of Dorsum sellae and posterior Sphenoid plane. Posterior Sphenoid plane was defined as the line between both blue circles, at the junctions of Dorsum sellae and Sphenoid bone and Sphenooccipital synchondrosis (SOS). SOSA: Spheno-occipital synchondrosis angle.

sellae and other in the projection of the synchondrosis sphenooccipitalis (SOS) (Figure 1). Dorsum sellae frequently have an erratic and independent orientation from the sphenoid plane.

3) Measurement of the angle between both bones adjacent of the SOS, sphenoid and the Pars basilaris of the occipital bone, sphenooccipitalis synchondrosis angle (SOSA) (Figure 2).

Irrespective of measurements angle quadrants, for better comprehension, all angles were measured as positive values. The SOSA angle was classified as flexed (>180 ${ }^{\circ}$ ), neutral or extended $\left(<180^{\circ}\right)$.

4) A correlation test was run between CBA and SOSA angles to investigate possible correlations between them (Figure 3).

The software for measuring the angular variables was the Meazure 2.0 software (C-Thing Software, Mountain View, CA, US, 2004). 


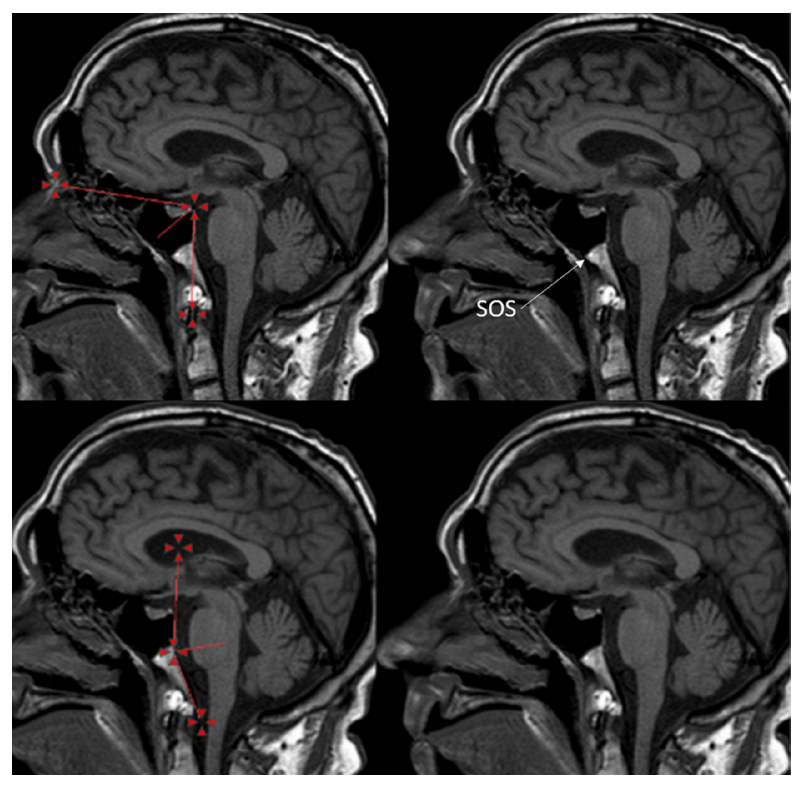

Figure 2. Cranial base angle (Upper left) and Sphenooccipitalis synchondrosis angle (Lower left). In the right side are depicted original image for detailed anatomical visualization.

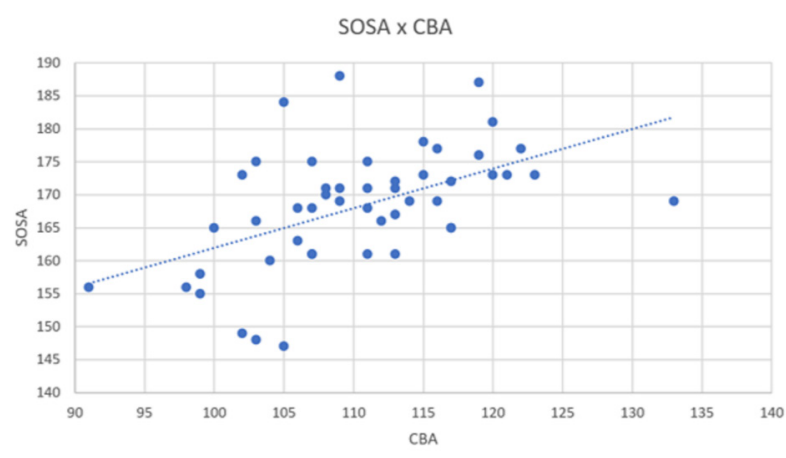

Figure 3. Correlation between cranial base angle (CBA) and sphenooccipital synchondrosis angle. (SOSA) $\mathrm{R}=0.51 ; \mathrm{p}<0.01$.

\section{Statistic}

Ages and gender were described as mean and standard deviation and absolute numbers, respectively.

The angles were described as minimum and maximum, mean and standard deviation. Regardless of the angle measurement quadrant, they were measured as positive values.
The distribution normality was evaluated by the Shapiro-wilk test. Both angular measures fitted normal distributions.

The correlation test used was the Pearson test.

The statistical software used was IBM SPSS Statistics for Windows, Version 20.0. Armonk, NY: IBM Corp.

\section{Ethics}

This work was carried out in accordance with national ethical standards, based on Resolution $N^{\circ}$ 510, dated April 7, 2016. Surveys conducted with a database containing associated information, with no possibility of individual identification.

\section{RESULTS}

Fifty (50) MR examinations of normal adults were evaluated (Table I).

The mean age of the subjects was $48.34 \pm$ 16.90. Twenty-eight of them were females.

\section{Localization of the flexion angle of the skull base}

The vertex of the skull base flexion angle in all individuals occurred in the sphenoid bone, in the projection of the top of Dorsum sellae. In no skull the flexion angle occurred in the SOS (Figure 1).

\section{Angular measurements}

The mean CBA was $110.32 \pm 7.75$, (91-113).

The mean SOSA were $167.48 \pm 9$ (147-188). Of the 50 measured angles, 3 were discretely flexed ( $6.3^{\circ}$ of flexion in average) (Figure 4), one was neutral (without flexion or extension), in the same angulation of the posterior sphenoid plane and, the remaining 46 (92\%) were extended. 
Table I. Demographic data: age and gender. Angles values. Classification of SOSA in flexed, extended or neutral.

\begin{tabular}{|c|c|c|c|c|c|}
\hline $\mathbf{N}$ & Gender & Age & CBA & SOSA & F/E/N \\
\hline 1 & Female & 64 & 115 & 173 & Extended \\
\hline 2 & Female & 55 & 123 & 173 & Extended \\
\hline 3 & Female & 48 & 115 & 178 & Extended \\
\hline 4 & Female & 13 & 105 & 184 & Flexed \\
\hline 5 & Female & 45 & 111 & 171 & Extended \\
\hline 6 & Female & 49 & 111 & 175 & Extended \\
\hline 7 & Female & 70 & 99 & 158 & Extended \\
\hline 8 & Female & 57 & 113 & 172 & Extended \\
\hline 9 & Female & 49 & 91 & 156 & Extended \\
\hline 10 & Male & 68 & 109 & 171 & Extended \\
\hline 11 & Male & 12 & 109 & 169 & Extended \\
\hline 12 & Female & 75 & 106 & 168 & Extended \\
\hline 13 & Male & 75 & 102 & 173 & Extended \\
\hline 14 & Female & 45 & 111 & 161 & Extended \\
\hline 15 & Female & 45 & 104 & 160 & Extended \\
\hline 16 & Male & 17 & 107 & 161 & Extended \\
\hline 17 & Male & 48 & 117 & 165 & Extended \\
\hline 18 & Male & 16 & 133 & 169 & Extended \\
\hline 19 & Female & 57 & 112 & 166 & Extended \\
\hline 20 & MALE & 32 & 116 & 177 & Extended \\
\hline 21 & MALE & 35 & 116 & 169 & Extended \\
\hline 22 & Female & 63 & 103 & 175 & Extended \\
\hline 23 & Female & 52 & 108 & 171 & Extended \\
\hline 24 & Female & 19 & 117 & 172 & Extended \\
\hline 25 & Female & 64 & 113 & 171 & Extended \\
\hline 26 & Male & 60 & 111 & 168 & Extended \\
\hline 27 & Female & 54 & 103 & 166 & Extended \\
\hline 28 & Female & 39 & 100 & 165 & Extended \\
\hline 29 & Female & 35 & 120 & 173 & Extended \\
\hline 30 & Female & 48 & 117 & 165 & Extended \\
\hline 31 & Female & 44 & 114 & 169 & Extended \\
\hline 32 & Female & 65 & 119 & 176 & Extended \\
\hline 33 & Female & 44 & 113 & 167 & Extended \\
\hline 34 & Female & 40 & 107 & 161 & Extended \\
\hline 35 & Female & 50 & 107 & 161 & Extended \\
\hline 36 & Male & 37 & 107 & 175 & Extended \\
\hline 37 & Male & 70 & 120 & 181 & Neutral \\
\hline 38 & Female & 56 & 121 & 173 & Extended \\
\hline 39 & Male & 36 & 109 & 188 & Flexed \\
\hline 40 & Female & 31 & 122 & 177 & Extended \\
\hline 41 & Male & 64 & 108 & 170 & extended \\
\hline 42 & Male & 57 & 107 & 168 & Extended \\
\hline 43 & Male & 72 & 106 & 163 & Extended \\
\hline 44 & Male & 21 & 102 & 149 & Extended \\
\hline 45 & Male & 64 & 113 & 161 & Extended \\
\hline 46 & Male & 52 & 119 & 187 & Flexed \\
\hline 47 & Male & 41 & 103 & 148 & Extended \\
\hline 48 & Male & 75 & 99 & 155 & Extended \\
\hline 49 & Male & 33 & 105 & 147 & Extended \\
\hline 50 & Male & 56 & 98 & 156 & Extended \\
\hline
\end{tabular}

CBA: Cranial base angle. SOSA: Angle of sphenooccipital synchondrosis. F/E/N: Classification of SOSA as flexed, extended or neutral. 


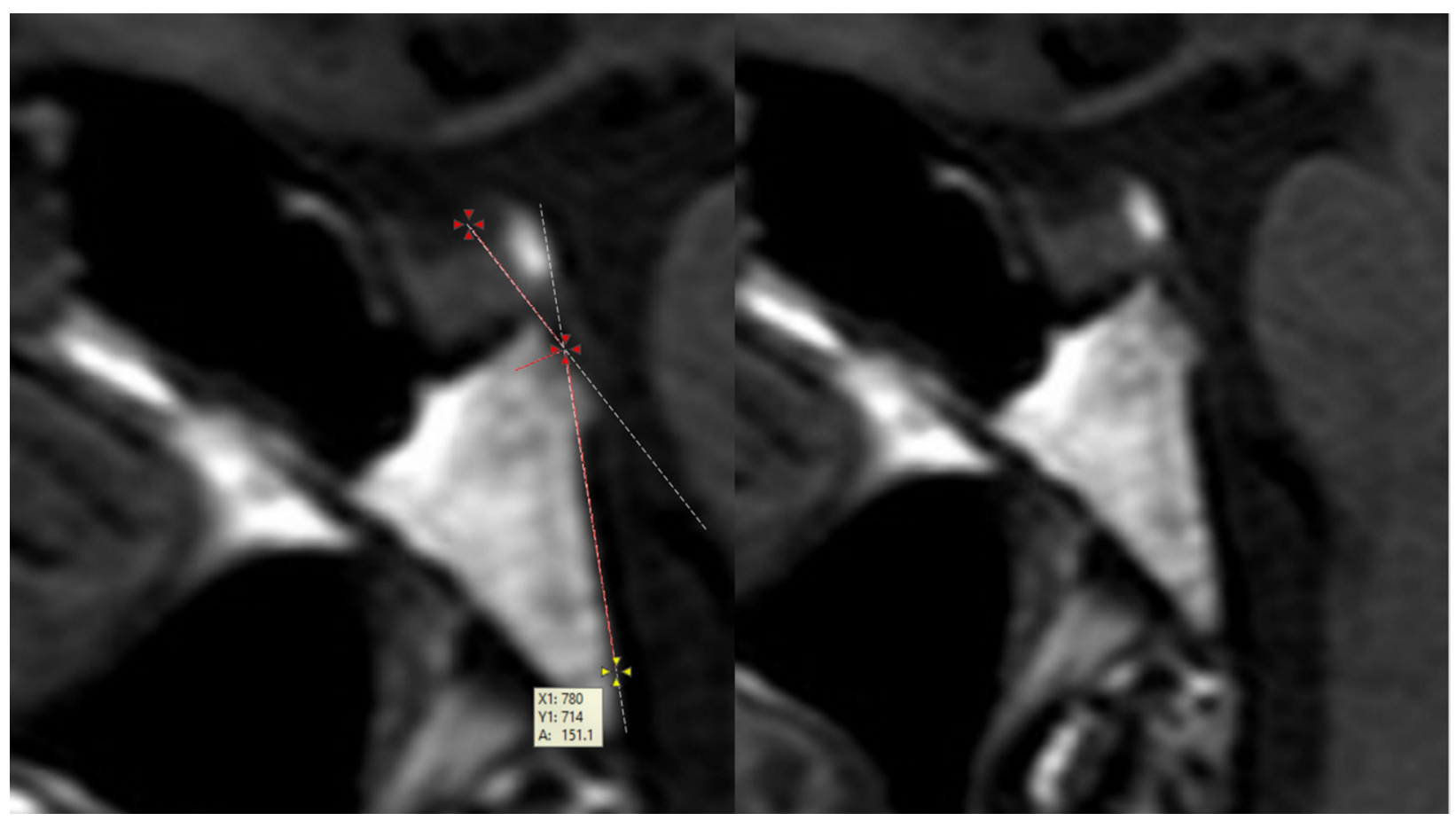

Figure 4. Image showing a flexed Spheno-occipital synchondrosis angle. At left angular measurement. At right side, original image for detailed anatomical visualization.

\section{Correlation between the CBA and SOSA}

A correlation test(Pearson)was performed between the CBA and SOSA angles (Figure 3): The correlation coefficient was 0.5189, $p<0.01$.Greater CBA angles had moreenlarged SOSA and vice versa. This correlation suggests the possibility of some regulation (or compensation) between the angles in the formation of the adult skull of normal humans.

\section{DISCUSSION}

In the embryology, the para-axial mesoderm participates in the formation of skull base up to the upper limit of the notochord. Above this point, the neural crest develops prechordal mesoderm.

Great amount of research has been done in the last decades evaluating CBA among various species of animals. The base of the human skull is the most angled among all the animals' species (Lieberman et al. 2000). Human CBA made possible a greater skull volume for larger brain, the development of human vocalization and acquisition of the erect position, among others.

Several works in CBA defines a plane between postchordal and the prechordal plate, especially in SOS (De Geus et al. 1938, Lieberman et al. 2000). Several authors suggest that CBA would be created in synchondroses, especially in SOS (Lieberman \& MacCarthy 1999).

According with these statements, flexion of the skull base would occur between the sphenoid bone and the Pars basilaris of the occipital bone.

In pre-human primates, CBA increases after birth, especially in SOS. In fact, great part of cranial base elongation has been made by synchondrosis growing (Lieberman et al. 2000). Probably the place of CBA angulation has been considered in the same way, for all animal 
species. This assumption may be adequate only for pre-homo sapiens species.

In our sample, CBA was created intrinsically in the sphenoid bone and SOS did not participate in cranial base flexion. Rather, SOS is suggestive to participate in the extension between pre and chordal plate bones. The apex of the CBA flexion angle was located within sphenoid bone, in all subjects.

Intrinsic developmental growth movements in sphenoid bone may also be responsible for CBA in humans (Latham 1972, Lieberman et al. 2000): The growing posterior border of the sphenoid bone, Dorsum sellae and later sphenoid growth zone of hypertrophiccartilage,midsph enoidal synchondrosis and sphenooccipital synchondrosis. In the last, growth on the sphenoidal side increase pre-sellarregion.

In anthropology, there are at least 17 different modes of CBA measurement (Botelho et al. 2018). Majority of studies used the "seal point "as the vertex of CBA in the nasion-sella-basion angle. In doing so, part of clival angulation may not make part of measurement and it ignores angulation made by dorsal surface of sphenoid.

Recently, in MRI for Clinical proposal, the cranial base angle has been measured by three points at the sagittal plane nasal bone, the top of Dorsum Sellae and Basion (Karagöz et al. 2002). For our study, the point located at the projection of frontonasalis suture, joined to the top of Dorsum sellae helped to delineate anterior cranial base plane.

Differences incranial base angulation by flexion and extension by bone drift probably occur at different sites and through different processes in humans and other primates (Lieberman et al. 2000).

In none of our MRI exams, the sphenooccipital synchondrosis contributed to the cranial base flexion.
In ninety-four (94)\% of MRI, the angle between clivus and sphenoid bone contributed to a discrete extension at the site of original sos. Only in three cases there was a discrete flexion ( $6.3^{\circ}$ in average) that did not contribute significantly to the CBA. Several studies demonstrate that cranial base retroflex rather than flex in human fetal period (Jeffery \& Spoor 2002, 2004, Karagöz et al. 2002). So, measurements made only between the dorsal sphenoidale plane and jugum sphenoidale would be adequate to measure the cranial base angulation. In this work, the rounded intrusive shape of sphenoid sinus making projection inside anterior skull base was not used.

Cranial base flexion probably is an intrinsic feature of predominantly genetically determined human beings (Cendekiawan et al. 2010).

There is some information from clinical scenario that also suggests the participation of the sphenoid CBA in the development: CHARGE syndrome occurs after mutations or deletions of the chromodomain-helicase-DNA binding protein 7 gene (CHD7) (De Geus et al. 1938). In this syndrome, morphologic changes in the Sphenoid bone create CBA enlargement (Platybasia) and great clival hypoplasia. Platybasia is the lack of adequate CBA development. It can be observed, from published images that, Platybasia was conditioned by enlarged CBA already in the inner sphenoid bone. The clivus in this syndrome is extremely hypoplastic and not developed.

In another syndrome, Cleft palate, the prevalence of (Nachmani et al. 2013) is greater than in controls [17]. Cleft palate is a problem originated by neural crest under- development. Neural crest cells develop craniofacial cartilage and chondrocranial bone above parachordal mesoderm and so, sphenoid bone.

In Basilar invagination (Botelho et al. 2018), a problem frequently associated with Platybasia 
in which the CBA is flattened, the preliminary evaluation of published images suggests that, in the same way, platybasic CBA were already defined in the intrinsic nature of sphenoid bone.

Cleft palate, CHARGE syndrome and basilar invagination are associated with Platybasia, lack of cranial base flexure and with clival underdevelopment. It is possible that lack of angulation in the bone sphenoid be associated with under-development of the clivus. The correlation between both CBA and SOSA suggested that may have some correlation between both angles or, Platybasia and underdevelopment of clivus may have a common pathophysiologi process.

These results have a potential clinical effect: Platybasia has gained progressive importance int the pathophysiology of Basilar invagination. With the advent of endoscopic approach rising the ability to decompress higher parts of cranial base, recreate cranial base flexion angle to allow craniospinal realignment perhaps may be a realistic possibility in a short future.

In conclusion, in the studied sample, the cranial base angle was created in the sphenoid bone in all cases. The flexion in skull base had a prechordal origin (in the inner sphenoid bone) rather than in the transition between prechordal and chordal plates.

\section{REFERENCES}

BOTELHO R, FERREIRA J \& ZANDONADI E. 2018. Basilar invagination: A Craniocervical Kyphosis. World Neurosurg 117: e180-e186.

CENDEKIAWAN T, WONG R \& RABIE A. 2010. Relationships between cranial base synchondroses and craniofacial development: a review. The Open Anatomy Journal 2: 67-75.

COULY G, COLTEY M \& LE DOUARIN N. 1993. The triple origin of skull in higher vertebrates: a study in quail-chick chimeras. Development 117: 409-429.

DE GEUS C, BERGMAN J, VAN RAVENSWAAIJ-ARTS C \& MEINERS LC. 1938. Imaging of Clival Hypoplasia in CHARGE Syndrome and Hypothesis for Development: A Case-Control Study. Am J Neuroradiol 39: 1938-1942.

JEFFERY N \& SPOOR F. 2002. Brain size and the human cranial base: a prenatal perspective. Am J Phys Anthropol 118: 324-340.

JEFFERY N \& SPOOR F. 2004. Ossification and midline shape changes of the human fetal cranial base. Am J Phys Anthropol 123: 78-90.

KARAGÖZ F, IZGI N \& KAPÍJCÍJOĞLU S. 2002. Morphometric measurements of the cranium in patients with Chiari type I malformation and comparison with the normal population. Acta Neurochir 144: 165-171.

LATHAM R. 1972. The Different Relationship of the Sella Point to Growth Sites of the Cranial Base in Fetal Life. J Dent Res 51(6): 1646-1650.

LE DOUARIN N, ZILLER C \& COULY G. 1993. Patterning of neural crest derivatives in the avian embryo: in vivo and in vitro studies. Dev Biol 159: 24-49.

LIEBERMAN D \& MCCARTHY R. 1999. The ontogeny of cranial base angulation in humans and chimpanzees and its implications for reconstructing pharyngeal dimensions. J Hum Evol 36: 487-517.

LIEBERMAN DE, ROSS CF \& RAVOSA MJ. 2000. Primate cranial base:ontogeny, function, and integration. Am J Phys Anthropol 113(Suppl 31): 117-169.

MCBRATNEY-OWEN B, ISEKI S, BAMFORTH S, OLSEN BR \& MORRISS-KAY GM . 2008. Development and tissue origins of the mammalian cranial base. Developmental Biology 322: 121-132.

MICHEJDA M. 1972. The Role of Basicranial Synchondroses in Flexure Processes and Ontogenetic Development of the Skull Base. Am J Phys Anthrop 37: 143-150.

NACHMANI A, AIZENBUD D, BERGERG, BERGER RL, HAZAN-MOLINA H \& FINKELSTEIN Y. 2013. The prevalence of Platybasia in patients with velopharyngeal incompetence. Cleft Palate Craniofac J 50(5): 528-534.

NIE X. 2005. Cranial base in craniofacial development: developmental features, influence on facial growth, anomaly, and molecular basis. Acta Odonto Scand 63: 127-135.

SEIFERT R, JACOB M \& JACOB H. 1993. The avian prechordal head region: a morphological study. J Anat 183: 75-89.

\section{How to cite}

BOTELHO RV, BOTELHO PB \& DINIZ JM. 2020. Where does the cranial base flexion take place in humans? An Acad Bras Cienc 92: e20190825. DOI. 10.1590/0001-3765202020190825. 
Manuscript received on September 7, 2019;

accepted for publication on October 3, 2019

\section{RICARDO V. BOTELHO ${ }^{1}$}

https://orcid.org/0000-0002-9018-2746

\section{PEDRO B. BOTELHO²}

https://orcid.org/0000-0003-3336-1913

\section{JULIETE M. DINIZ3}

https://orcid.org/0000-0003-4166-5706

${ }^{1}$ Programa de Pós-Graduação, Instituto de Assistência ao Servidor Público Estadual/ IAMSPE, Rua Tuim,

585, 122A, 04514-102 São Paulo, SP, Brazil

${ }^{2}$ Faculdade de Ciências Médicas da Santa Casa de São Paulo, Rua Prof. Dr. Haberbeck Brandão, 68, 04027-040 São Paulo, SP, Brazil

${ }^{3}$ Programa de Pós-Graduação, Instituto de Assistência ao Servidor Público Estadual/ IAMSPE, Avenida Ibirapuera, 981, 04029-000 São Paulo, SP, Brazil Correspondence to: Ricardo Vieira Botelho

E-mail:bitbot@uol.com.br

\section{Author contributions}

RB: contributed to the design and conduct of the manuscript. PB: contributed to the development of the method and angular measures. JD: contributed with angular measures and text development.

\section{(c) BY}

